\title{
Restarting oral anticoagulants after intracerebral hemorrhage: cons
}

\author{
Silvia Ricci · Francesca Pistoia • Antonio Carolei • \\ Simona Sacco
}

Received: 11 November 2014/ Accepted: 14 November 2014/Published online: 28 November 2014 (C) SIMI 2014

Keywords Intracerebral hemorrhage · Atrial fibrillation · Anticoagulants - Thromboembolic risk

Oral anticoagulant therapy is an effective treatment for stroke prevention in patients with atrial fibrillation and other forms of cardiac sources of embolism. However, vitamin $\mathrm{K}$ antagonists (VKAs) and novel direct oral anticoagulants (NOACs), such as direct thrombin inhibitors or direct factor Xa inhibitors, are associated with an increased bleeding risk, including intracerebral hemorrhage (ICH). In the absence of a previous history of $\mathrm{ICH}$, reduction in the risk of thromboembolic events outweighs the increased risk of ICH. In subjects with previous $\mathrm{ICH}$, the equilibrium changes and the risk/benefit ratio is unpredictable since those subjects were excluded from clinical trials on the prevention of thromboembolic events with oral anticoagulants. Even in the absence of reliable research data, it is widely accepted that anticoagulants should not be resumed in the acute stroke phase for the risk of hematoma expansion and early re-bleeding [1]. At variance, long-term prophylaxis is concerned and opinions are controversial; guidelines do not, in most cases, deal with this issue or in cases where they do, the level of evidence is generally low [1-3].

Some observational studies have evaluated the possible risks or benefits of resuming the use of anticoagulants in subjects with ICH [4-8]. Those studies are somewhat conflicting, and their results are of limited utility in clinical

S. Ricci · F. Pistoia · A. Carolei · S. Sacco $(\square)$ Department of Applied Clinical Sciences and Biotechnology, Institute of Neurology, University of L'Aquila, via Vetoio, 67100 L'Aquila, Italy

e-mail: simona.sacco@cc.univaq.it practice since in some instances studies only provide the risk of hemorrhagic but not of thrombotic events, only address the incidence of recurrences without taking into account other major outcomes such as mortality and disability, have a retrospective design, or lack statistical power. In addition, in all those studies, the subjects who resumed anticoagulants were not randomly selected. Consequently, results are not generalizable since only subjects considered at low bleeding risk had probably been selected to resume this treatment.

Further data, from randomized studies, are needed to establish the optimal treatment for subjects with a cardiac source of embolism who had an ICH. Nonetheless, in our opinion, at the present state of our knowledge, the use of anticoagulants should be avoided in most if not in all subjects with $\mathrm{ICH}$ in the presence of a cardiac source of embolism, since patients would be exposed to the deadliest and least treatable type of stroke event. Actually, even in subjects who do not use anticoagulants, ICH is the deadliest form of stroke with a 30-day case-fatality-rate close to $50 \%$ [9, 10] while for ischemic stroke associated with atrial fibrillation, the 30-day case-fatality rate is equal to approximately $30 \%$ [11]. In anticoagulant users, compared with non-users, hematoma volume is higher, and there is also an increased rate of early hematoma expansion [12]. This correlates with a worse clinical outcome in anticoagulant-related $\mathrm{ICH}$ than in spontaneous ICH [12]. Up to $76 \%$ of patients with VKA-associated ICH may have severe disability or may die in the short term [13]. Mortality rates remain high and clinical outcomes generally remain poor despite reversal of anticoagulation [14]. Although NOACs have been associated with a reduced risk of ICH in clinical trials, we do not yet know if this reduced risk also applies to subjects with a previous $\mathrm{ICH}$ since they were excluded from those studies. Despite the reduced $\mathrm{ICH}$ 
occurrence associated with NOAC, those drugs have not been associated with reduced mortality rates compared to warfarin [15]. We should also consider that if the patient has a recurrent ICH we do not have any treatment that can significantly improve the prognosis, while if the patient has an ischemic event thrombolysis, within the appropriate time window, can significantly improve the prognosis. The probability of harming patients may be even higher in subjects with lobar ICH. The location of ICH may reflect the underlying microvascular pathology, which is amyloid angiopathy for most cases of lobar ICH occurring in subjects aged $>55$ years, while for deep ICH it is arterial hypertension. Lobar ICH is associated with a higher probability of re-bleeding compared to deep hemispheric $\mathrm{ICH}$, with a 1-year risk of recurrence of 15 and $2.1 \%$, respectively [16]. Antihypertensive therapy likely reduces the risk of recurrence in patients with hypertensive hemorrhage. Unfortunately, there is currently no way to modify the risk of ICH associated with cerebral amyloid angiopathy. This concept is also supported by data from a decision analysis model based on retrospective data that suggest that in settings in which the risk of ICH recurrence is high, such as in lobar ICH, the increased mortality associated with warfarin ICH is itself sufficient to argue against anticoagulation, while risks and benefits of anticoagulation are more closely balanced when applied to patients with deep hemispheric ICH [17].

In patients with atrial fibrillation, the thromboembolic and hemorrhagic risk has been classically estimated using the $\mathrm{CHADS}_{2}$ or $\mathrm{CHA}_{2} \mathrm{DS}_{2}$-VASc and HAS-BLED score systems, respectively. A favorable balance for resuming anticoagulants has been suggested when $\mathrm{CHADS}_{2}$ score is $\geq 4$ or $\mathrm{CHA}_{2} \mathrm{DS}_{2}$-VASc score is $\geq 5$ with a risk of ischemic stroke $>6.5 \%$ per year and the HAS-BLED is $\leq 3$ [18-20]. However, in our opinion this paradigm is not unconditionally true; secondary rather than primary ischemic stroke prevention is a stronger indication for resuming anticoagulants, and a CHADS 2 score $\geq 4$ is not necessarily indicative of a previous stroke, while the HAS-BLED scoring does not consider the risk associated with a previous ICH. Based on these data, if we try to define the characteristics of a patient for whom it is relatively safe to resume anticoagulation after an $\mathrm{ICH}$, we should consider a patient with a previous ischemic stroke, a deep ICH and a good blood pressure control, a typical scenario of the minority of cases. In addition, the risk of new intracranial bleeding associated with resumption of anticoagulants may be magnified in the elderly because of the increased risk of falls, the presence of comorbidities (shared risk factors for ischemic and hemorrhagic stroke), the poor compliance to therapy or polytherapy, and the presence of white matter lesions and microbleeds. All these factors are more common with increasing age.
In conclusion, we want to underscore that the chance to have an ICH and to require anticoagulants for cardioembolism is an extremely difficult situation for the patient and for the physician who has to take a troublesome decision. At the moment, while hoping for new clinical evidence to emerge, we suggest to avoid the prescription of a treatment that may contribute to worsening of the natural history of our patients.

\section{Conflict of interest None.}

\section{References}

1. Morgenstern LB, Hemphill JC 3rd, Anderson C, Becker K, Broderick JP, Connolly ES Jr, Greenberg SM, Huang JN, MacDonald RL, Messé SR, Mitchell PH, Selim M, Tamargo RJ (2010) Guidelines for the management of spontaneous intracerebral hemorrhage: a guideline for healthcare professionals from the American Heart Association/American Stroke Association. Stroke 41:2108-2129

2. Kernan WN, Ovbiagele B, Black HR, Bravata DM, Chimowitz MI, Ezekowitz MD, Fang MC, Fisher M, Furie KL, Heck DV, Johnston SC, Kasner SE, Kittner SJ, Mitchell PH, Rich MW, Richardson D, Schwamm LH, Wilson JA (2014) Guidelines for the prevention of stroke in patients with stroke and transient ischemic attack: a guideline for healthcare professionals from the American Heart Association/American Stroke Association. Stroke 45:2160-2236

3. Meschia JF, Bushnell C, Boden-Albala B, Braun LT, Bravata DM, Chaturvedi S, Creager MA, Eckel RH, Elkind MS, Fornage M, Goldstein LB, Greenberg SM, Horvath SE, Iadecola C, Jauch EC, Moore WS, Wilson JA (2014) Guidelines for the primary prevention of stroke: a statement for healthcare professionals from the American Heart Association/American Stroke Association. Stroke 45 (in press)

4. Claassen DO, Kazemi N, Zubkov AY, Wijdicks EF, Rabinstein AA (2008) Restarting anticoagulation therapy after warfarinassociated intracerebral hemorrhage. Arch Neurol 65:1313-1318

5. Gathier CS, Algra A, Rinkel GJ, van der Worp HB (2013) Longterm outcome after anticoagulation-associated intracerebral haemorrhage with or without restarting antithrombotic therapy. Cerebrovasc Dis 36:33-37

6. Majeed A, Kim YK, Roberts RS, Holmström M, Schulman S (2010) Optimal timing of resumption of warfarin after intracranial hemorrhage. Stroke 41:2860-2866

7. Poli D, Antonucci E, Dentali F, Erba N, Testa S, Tiraferri E, Palareti G, Italian Federation of Anticoagulation Clinics (FCSA) (2014) Recurrence of ICH after resumption of anticoagulation with VK antagonists: CHIRONE study. Neurology 25:1020-1026

8. Yung D, Kapral MK, Asllani E, Fang J, Lee DS; Investigators of the Registry of the Canadian Stroke Network (2012) Reinitiation of anticoagulation after warfarin associated intracranial hemorrhage and mortality risk: the Best practice for reinitiating anticoagulation therapy after intracranial bleeding (BRAIN) study. Can J Cardiol 28:333-339

9. Sacco S, Marini C, Toni D, Olivieri L, Carolei A (2009) Incidence and 10-year survival of intracerebral hemorrhage in a population-based registry. Stroke 40:394-399

10. Sacco S, Stracci F, Cerone D, Ricci S, Carolei A (2011) Epidemiology of stroke in Italy. Int J Stroke 6:219-227

11. Marini C, De Santis F, Sacco S, Russo T, Olivieri L, Totaro R, Carolei A (2005) Contribution of atrial fibrillation to incidence 
and outcome of ischemic stroke: results from a population-based study. Stroke 36:1115-1119

12. Cucchiara B, Messe S, Sansing L, Kasner S, Lyden P, The CHANT Investigators (2008) Hematoma growth in oral anticoagulant related intracerebral hemorrhage. Stroke 39:2993-2996

13. Fang MC, Go AS, Chang Y, Hylek EM, Henault LE, Jensvold NG, Singer DE (2007) Death and disability from warfarin-associated intracranial and extracranial hemorrhages. Am J Med 120:700-705

14. Dowlatshahi D, Kosior JC, Idris S, Eesa M, Dickhoff P, Joshi M, Subramaniam S, Tymchuk S, Hill MD, Aviv RI, Frayne R, Demchuk AM (2012) Planimetric hematoma measurement in patients with intraventricular hemorrhage: is total volume a preferred target for reliable analysis? Stroke 43:1961-1963

15. Hart RG, Diener HC, Yang S, Connolly SJ, Wallentin L, Reilly PA, Ezekowitz MD, Yusuf S (2012) Intracranial hemorrhage in atrial fibrillation patients during anticoagulation with warfarin or dabigatran: the RE-LY trial. Stroke 43:1511-1517

16. Flaherty ML, Woo D, Broderick J (2006) The incidence of deep and lobar intracerebral hemorrhage in whites, blacks, and Hispanics. Neurology 28:956-957
17. Eckman MH, Rosand J, Knudsen KA, Singer DE, Greenberg SM (2003) Can patients be anticoagulated after intracerebral hemorrhage? A decision analysis. Stroke 34:1710-1716

18. Olesen JB, Lip GY, Lindhardsen J, Lane DA, Ahlehoff O, Hansen ML, Rauns $\varnothing$ J, Tolstrup JS, Hansen PR, Gislason GH, Torp-Pedersen C (2011) Risks of thromboembolism and bleeding with thromboprophylaxis in patients with atrial fibrillation: a net clinical benefit analysis using a 'real world' nationwide cohort study. Thromb Haemost 106:739-749

19. Olesen JB, Torp-Pedersen C, Hansen ML, Lip GY (2012) The value of the $\mathrm{CHA}_{2} \mathrm{DS}_{2}$-VASc score for refining stroke risk stratification in patients with atrial fibrillation with a $\mathrm{CHADS}_{2}$ score 0-1: a nationwide cohort study. Thromb Haemost 107:1172-1179

20. Pisters R, Lane DA, Nieuwlaat R, de Vos CB, Crijns HJ, Lip GY (2010) A novel user-friendly score (HAS-BLED) to assess 1-year risk of major bleeding in patients with atrial fibrillation: the Euro hearth survey. Chest 138:1093-1100 